2016-06-06

\title{
High-mobility of unconstrained rock
}

avalanches: Numerical simulations of a

laboratory experiment and an

\section{Argentinian event}

Manzella, Irene

http://hdl.handle.net/10026.1/16000

$10.1201 / \mathrm{b} 21520-164$

LANDSLIDES AND ENGINEERED SLOPES: EXPERIENCE, THEORY AND PRACTICE, VOLS 1-3

CRC Press

All content in PEARL is protected by copyright law. Author manuscripts are made available in accordance with publisher policies. Please cite only the published version using the details provided on the item record or document. In the absence of an open licence (e.g. Creative Commons), permissions for further reuse of content should be sought from the publisher or author. 


\title{
High-mobility of unconstrained rock avalanches: numerical simulations of a laboratory experiment and an Argentinian event
}

\author{
I. Manzella \\ Department of Earth Sciences, University of Geneva, rue des Maraîchers 13, 1205 Geneva, Switzerland
}

I. Penna

Geological Survey of Norway, Leiv Eirikssons vei 39, 7040 Trondheim, Norway

K. Kelfoun

Laboratoire Magmas et Volcans, Université Blaise Pascal, Clermont-Ferrand, France

\author{
M. Jaboyedoff \\ Center for Research on Terrestrial Environment, University of Lausanne, 1015 Lausanne, Switzerland
}

\begin{abstract}
Rock avalanches are one of the most hazardous landslide phenomena. They involve huge, extremely rapid flowing masses, carrying a strong power of destruction and reaching high mobility. The present article shows results of back-analysis of the Potrero de Leyes case in the Argentinian Andes. This rock avalanche has travelled on an unconstrained topography showing a great mobility, even without any channelizing effects. Simulations are carried out with VolcFlow, a continuum model, first on an unconstrained granular flow experiment and then on Potrero de Leyes. Results show that frictional model works well for the experiment, but that it can only reproduce the longitudinal runout in the field, and this provided that the basal friction angle used is close to the corresponding measured Fahrböschung. Here, where the rock avalanche starts as a coherent mass that disaggregates and shatters only during its propagation, lateral spreading is overestimated and a viscous behavior produces better results.
\end{abstract}

\section{INTRODUCTION}

Varnes (1978) and then Cruden and Varnes (1996) in their classification defined flow-type landslide as "spatially continuous movement in which surfaces of shear are short-lived, closely spaced, and usually not preserved. The distribution of velocities in the displacing mass resembles that in a viscous liquid". In this category are included a wide range of phenomena from sand and clay flows to debris flows and rock avalanches (Hungr et al., 2005, Hungr et al., 2013).

Rock avalanches, i.e. flows of fragmented rock derived from a bed-rock failure (Manzella et al., 2013), are amongst the most hazardous flow-type landslides.

These hazardous flows are characterized by extremely rapid, massive, flow-like motion that could be lethal and destructive: they can travel for several kilometres along mountains slopes and valleys. Their speed can exceed $100 \mathrm{~km} / \mathrm{hr}$ and the large quantity of mass in movement has tremendous power of destruction that can cause irreparable damage, changes in the landscape and a large number of fatalities, destroying entire villages and burying thousands of people. Among the most catastrophic examples the Khait rock avalanche (Tajikistan) in 1949, destroyed the entire town of Khait with the loss of 12'000 persons (Evans et al., 2009).

High-mobility of this type of flow is usually characterized by a large runout, i.e. the horizontal travel distance between the head scarp and the toe of the deposit, by a low apparent friction angle or Fahrböschung (Heim, 1932), i.e. respectively the angle and the tangent of the angle to the horizontal of the straight line connecting the top of the mass before failure and the distal end of the deposit, or by a low travel angle (Corominas, 1996), i.e. the angle of the energy line, i.e. the angle between the horizontal and the straight line connecting the centre of mass at start and after deposition (Manzella, 2008). In particular it is difficult to explain the highmobility of dry rock avalanches since the presence of water and, as a consequence, its fluidising and liquefying effects are negligible.

According to Nicoletti and Sorriso-Valvo (1991) geomorphological features are closely related to the mobility of rock avalanches. As reported by Manzella (2008), they distinguished rock avalanches in high, intermediate and low mobility ones. The first ones dissipate less energy during propagation, which happened usually in channelized narrow valley before spreading and stopping on a planar surface. This gives them a typically hour glass shape (see figure 1a). One case history of this type is the Pandemonium creek rock avalanche (fig. 1a) which took place in the southern Coast Mountains of British Columbia in 1959 (Evans et al., 1989). Intermediate mobility rock avalanches dissipate moderate energy during the spreading on a broad valley. They are also called unconstrained rock avalanches, which are the object of the present paper, and they are 
characterized by a nearly oval, trapezoidal or tongue shape (see figure 1b). The Frank slide (fig. 1b), which took place in 1903 in the southern Rocky Mountains of Canada, is an example of this kind of rock avalanche (Cruden and Martin, 2007, Charrière et al., 2016). Finally, the low mobility ones are characterized by a reverse T-shape (see figure 1c), caused by the high energy dissipating impact with the opposite slope. A typical example is the Valpola rock avalanche (see figure 1c), which took place in Italy in 1987 (Azzoni et al., 1992). a)

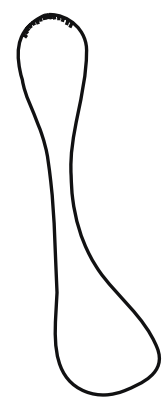

b)
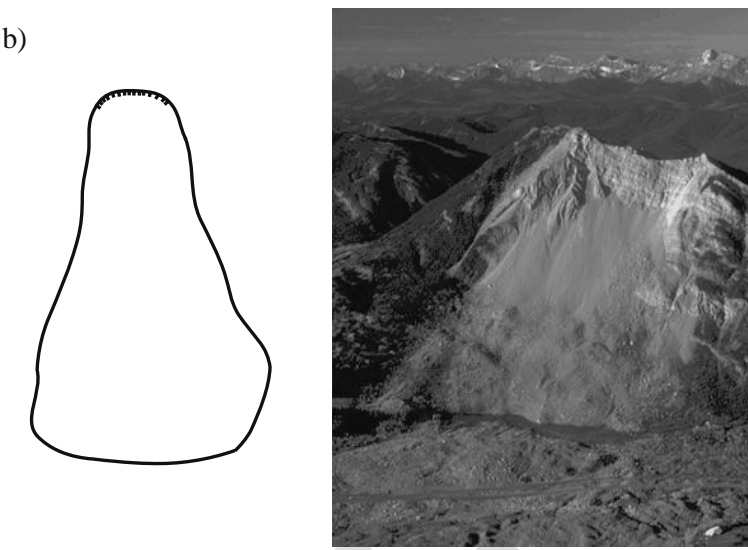

c)

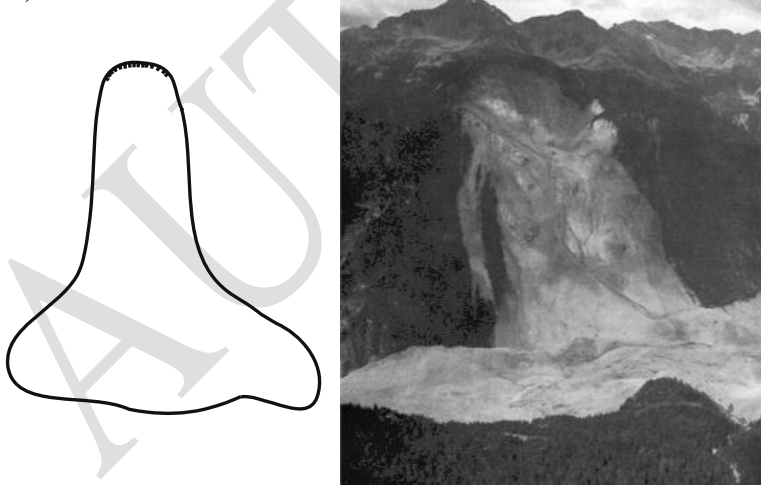

Figure 1. Sketches of typical shapes and picture of related examples of rock avalanches according to the classification of Nicoletti and Sorriso-Valvo (1991) and Corominas (1996): a) Hour glass shape and Pandemonium creek rock avalanche (source: Province of British Columbia); b) trapezoidal shape and Frank slide rock avalanche (source: Alberta Community Development); c) inverse $\mathrm{T}$ shape and Valpola rock avalanche (source: Azzoni et al, 1992). Adapted from Manzella (2008).
Several models have been developed to try to simulate the propagation of these dangerous and high-mobile phenomena. In particular, because of their flow-like behaviour, continuum mechanics models based on the St Venant equations of unsteady flow and on the work of Savage and Hutter (1989) are often used to model their propagation, e.g. Hungr (1995); Mangeney-Castelnau et al. (2005); Pirulli and Mangeney (2008); Pudasaini and Hutter (2007). In order to be able to use them in a hazard predictive perspective, models validation on laboratory experiments and back-analysis of cases history become crucial, e.g. (Constantinescu et al., 2011). They improve our understanding of the most suitable rheology and of the propagation and emplacement processes. They help us detecting advantages and limits of the different codes, refining their development and employment and consequently improving modelling and assessment of area at risk.

In the present study an unconstrained granular flow experiment carried out at the University of Geneva and the case of Potrero de Leyes rock avalanche were considered. This case history was chosen because, even if data available are limited and the accuracy is not very high, it represents a rare case of a well-preserved unconstrained rock avalanche. This event is very interesting to be studied since even if there is not a channelizing effect and it belongs to the aforementioned category of intermediate mobility flows, it happened to have a very low Fahrböschung. In addition unconstrained granular flows pose often problems to numerical modelers because of the difficulty in simulating lateral spreading with the lack of topographical constrains.

To back-analyse these data a continuum mechanics model developed at the Laboratoire Magmas et Volcans (Clermont-Ferrand, France), VolcFLow (Kelfoun and Druitt, 2005, Kelfoun et al., 2009), was used. Main parameters were changed and different rheologies were tested to try to fit not only the runout and spreading of the mass but also the thickness of the final deposit. This has allowed improving our understanding of unconstrained type of flow and to have an idea of the kind of rheology that could be used for a first approximation hazard assessment in the region of interest.

\section{METHOD AND DATA}

\subsection{VolcFlow}

VolcFlow is a continuum mechanics model based on the depth-averaged approximation which uses a topography-linked coordinate system, with $\mathrm{x}$ and $\mathrm{y}$ parallel to the local ground surface and $h$ vertical to it (Kelfoun et al., 2009), as shown with the grey line on the sketch on Figure 2. 
The general equation used for the stress is the following:

$$
=h \tan \left({ }_{b e d}\right) \times\left(u^{2} c u r b+g \cos \right)+{ }_{0}+\frac{d u}{d h}+u^{2} C
$$

where $\rho$ is the density, $\varphi_{\text {bed }}$ is the basal coefficient of friction, $u$ is the velocity, curb is the curvature of the topography in the flow, $g$ is the acceleration of gravity, $\tau_{0}$ is the cohesion, $\eta$ the viscosity, $\alpha$ is the slope angle and $C$ is the turbulence coefficient.

In this way Volcflow can simulate different behavior, i.e. frictional (with one or two friction angles), viscous, Bingham, Voellmy. According to (Kelfoun et al., 2009) the internal friction $\left(\varphi_{\text {int }}\right)$ is used to calculate the earth pressure coefficient, i.e. the ratio of ground-parallel to ground-normal stress as defined by Iverson and Denlinger (2001). The code works on MATLAB, the user needs to define the input file to run the simulations.

In the present study a script has been built to execute multiple runs, varying the different parameters in a systematic way.

\subsection{Laboratory experiment}

Unconstrained granular flows are largely used in laboratory analogue experiments to carry out parametrical study on rock avalanche propagation, e.g. (Davies and McSaveney, 1999, Friedmann et al., 2006, Longchamp et al., 2011, Manzella and Labiouse, 2008b, Pudasaini and Hutter, 2007). Here we have chosen to carry out an unconstrained flow experiment with glass beads in order to see how VolcFlow simulates a well-characterized case.

The set-up used for this purpose, and illustrated in figure 2 , consists in an inclined panel at $40^{\circ}$, where the material is released, followed by a horizontal one. The fall height is fixed at $0.695 \mathrm{~m}$.
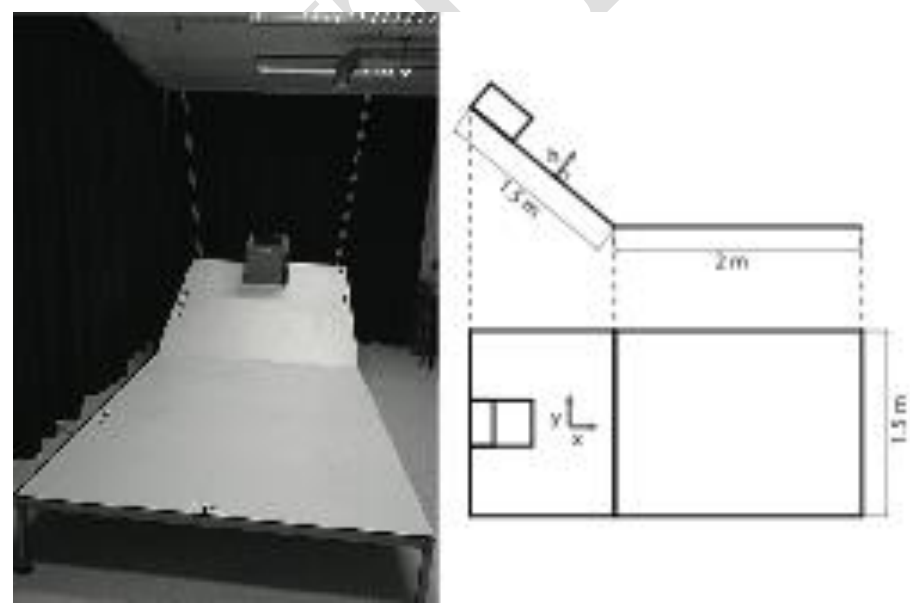

Figure 2. Picture and sketch with lateral and horizontal view of the set-up used to carry out the unconstrained granular flow experiments at the Geophysical Fluid Dynamics laboratory at the University of Geneva
Glass beads used are manufactured spheres of $2 \mathrm{~mm}$ diameters, with a bulk density of around 1600 $\mathrm{kg} / \mathrm{m}^{3}$. With several tilting tests a basal friction angle of $21^{\circ}$ has been estimated. An optical method called fringe projection method (see Manzella and Labiouse (2008a) and Manzella and Labiouse (2009) for more details), has been used to retrieve the 3D model of the final deposit.

A small volume of 0.001 cubic meters has been used.

\subsection{Potrero de Leyes}

Several historical rock avalanches have been registered in the Central Argentinian Andes, where the tectonic deformation has enhanced the rock mass degradation and the increase in slope instabilities occurrence over the years (Penna et al., 2015a, Penna et al., 2015b). On the other hand the low density of population, along with the difficulty to reach several sites and the lack of high definition data has contributed in the moderate interest that researchers have brought to this area in the past and to the limited amount of existing studies on Argentinian rock avalanches. Nevertheless often deposit outcrops show well-preserved features and characteristics that could constitute interesting case study and benchmark case. In addition historic rock avalanches in the Andean Cordillera have blocked several watercourses causing multiple natural dams, whose failure represent a serious threat for the urbanized area in the valleys downhill (Hermanns et al., 2011, Penna et al., 2013).

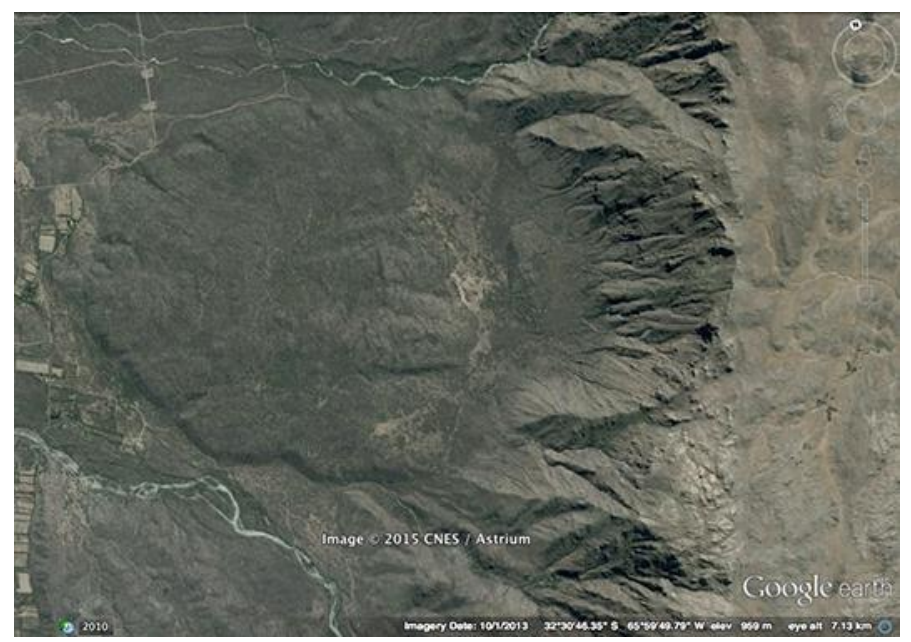

Figure 3. Potrero de Leyes rock avalanche. Source: $32^{\circ} 30^{\prime} 46.35^{\prime}$ S and 65 $59^{\prime} 49.79^{\prime}$ 'W. Google Earth.

In this framework it becomes important to study rock avalanches even in this apparently secluded area, not only because of the lessons they could teach us in terms of mechanisms and emplacement process, but also to be able to assess the hazard assessment related to the failure of landslide-dammed lakes. 
According to Penna et al. (2015a), the Potrero de Leyes rock avalanche in the San Luis Range $\left(32^{\circ} 30^{\prime} 30^{\prime \prime} \mathrm{S}\right.$; $66^{\circ} 0^{\prime} 0$ "'W; Figure 3$)$ is dated between $32.7 \pm 6.7$ and $40.8 \pm 8.6 \mathrm{ka}$ and it was triggered by seismic activity. The triggered volume has been estimated to be around $0.23 \mathrm{~km}^{3}$ using the Sloping Local Base Level (SLBL) methodology (Jaboyedoff and Derron, 2005), the mass propagated over an area of $8.8 \mathrm{~km}^{2}$, taking into account from the top scar to the final deposition zone. Field work and remote sensing technique have also allowed Penna et al. (2015a) to assess deposit thickness, geomorphology and main geometrical features. A maximum thickness of $100 \mathrm{~m}$ has been detected, whereas the apparent friction angle was estimated to be $9^{\circ}$ and the Fahrböschung 0.16 (travel distance 5100 meters and vertical drop 830 meters), which represents a very high mobility of the rock avalanche. This is even higher than the mobility predicted by Scheidegger (1973) with his empirical relationship between the volume and the Fahrböschung that estimated a value of about $0.21\left(12^{\circ}\right)$ for a $0.23 \mathrm{~km}^{3}$ volume. The travel angle was also estimated to be very low, around $6^{\circ}$, showing that the whole mass was characterized by an impressive mobility. On the other hand according to the abovementioned classification (Nicoletti and Sorriso-Valvo, 1991) this event is a typically tongue shaped rock avalanche (Fig. 1b), belonging to the intermediate mobility type.
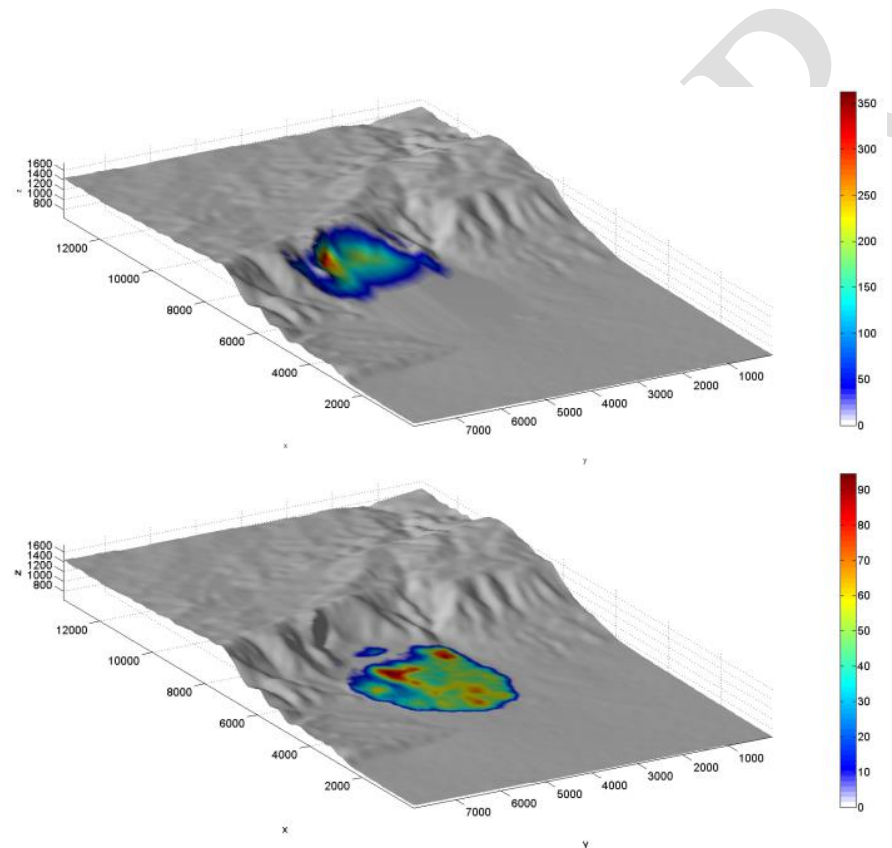

Figure 4. Reconstructed digital terrain model (DEM) before (above) and after (below) the Potrero de Leyes rock avalanche. The source area is in coulour on the pre-event topography

Because of the lack of recent measures and the limited accessibility to the area, the only digital elevation model available to the authors for this area has a 65 meters precision (source: http://srtm.usgs.gov/). This is not very high but it allows reproducing the main topographical features useful for the purpose of the present study simulations. In Figure 4 the reconstructed digital elevation model before and after the event are represented. The source area is also highlighted.

\section{RESULTS}

\subsection{Simulations of an unconstrained flow experiment}

Simulation of the laboratory granular flow test has been carried out with a simple frictional rheology and without any calibration to obtain a so-called class A prediction, i.e. simulations were carried using input parameters which were not back-analysed, material characteristics were measured with laboratory dedicated tests. Results are shown in Figure 5.

It can be seen that the total runout and width are well reproduced by the VolcFlow simulation. In fact the travel distance is of about $0.7 \mathrm{~m}$ from the slope break in both cases and the lateral spreading reaches also about $0.7 \mathrm{~m}$. The rendering given by the fringe projection method has an accuracy, which does not allow detecting the one particle layer at the border of the deposit. So the final width is more detectable in figure $5 \mathrm{a}$ on the picture of the deposit taken from above. Also the value and the localization of the greatest thickness of the deposit are well spotted, respectively around $1 \mathrm{~cm}$ and at 0.55 meters from the slope break. On the other hand the length $(0.3 \mathrm{~m}$ against $0.4 \mathrm{~m}$ in the experiment) and the shape of the deposit are not well reproduced. In the numerical simulations the mass is much more concentrated and has a more regular shape.

\subsection{Simulations of Potrero de Leyes}

For the back analysis of Potrero de Leyes rock avalanche first a simple frictional rheology has been considered and a script varying the basal friction has been run. A friction angle of $9^{\circ}$ has given the best fit for the longitudinal runout (see relative plots in figures 6 and 7). This angle corresponds to the measured Fahrböschung. On the other hand most of the mass remains in the upper part of the slope and cannot overcome the higher central part of the topography and the lateral spreading is overestimated. 


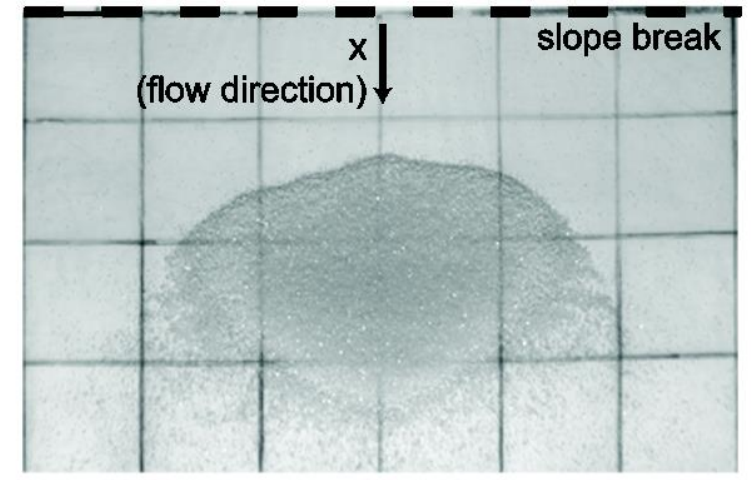

a. experiment: picture from above

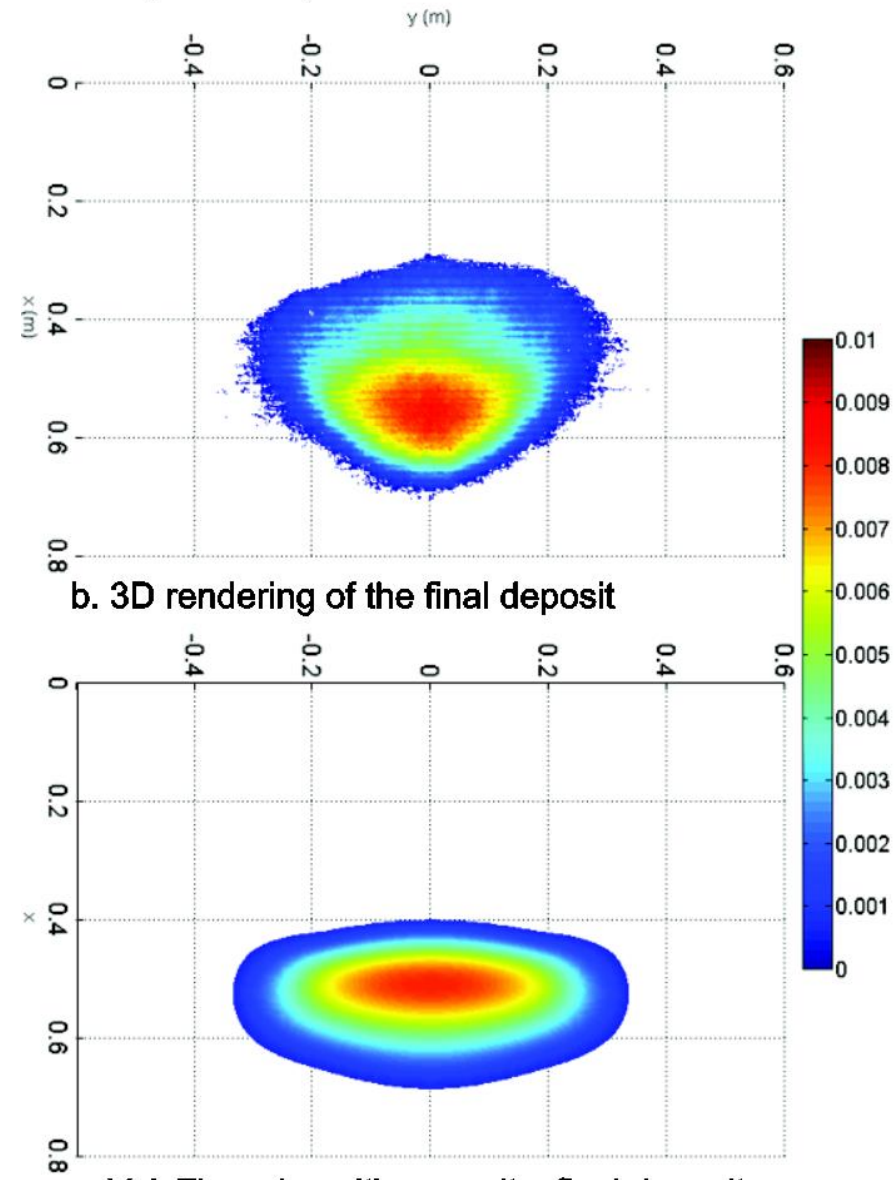

c. VolcFlow simualtion results: final deposit

Figure 5. Picture, rendering and results of the class A simulation of the laboratory glass beads flow deposit.

When a Voellmy type of behavior is assumed we need to reduce even further the basal friction in order to reproduce the total travel distance. An example is shown in the plots in figures 6 and 7 where the friction angle is fixed to $7^{\circ}$ and $\mathrm{C}$, the turbulence coefficient, is 0.05. Again also in this case lateral spreading and deposit thickness cannot be reproduced and the mass remains held back by the topographical bump in the central part of the slope.

The only way for the mass to overcome this central hill and still have a good fit with respect of the runout in simulations is to reduce the basal friction angle to approximately 3 degrees and to increase strongly either the cohesion or the viscosity (see for example plots in figure 6 and 7 with a viscosity of up to $\left.2 \cdot 10^{5} \mathrm{~Pa} \cdot \mathrm{s}\right)$. Nevertheless the lateral spreading is still largely overestimated.

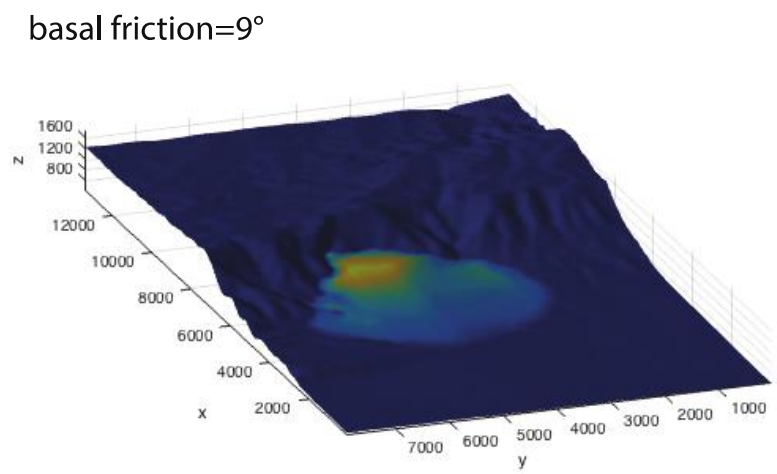

basal friction $=7^{\circ}, \mathrm{C}=0.05$

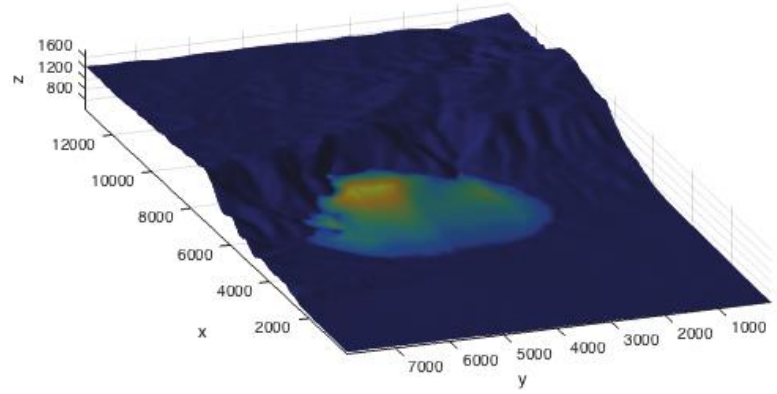

basal friction $=3^{\circ}$, viscosity $=2 \times 10^{\wedge} 5$

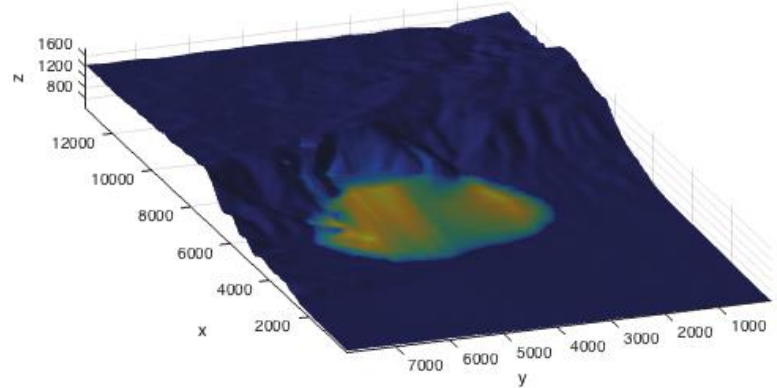

Figure 6. Final deposit of simulation with different rheology

\section{DISCUSSION AND CONCLUSION}

The present paper shows results of back analyses with a continuum model of two unconstrained flows: a laboratory experiment made with glass beads and a historic event in the Central Argentinian Andes.

For what concerns the laboratory experiments a class A simulation has given very good results in terms of travel distance, lateral spreading and maximum thickness with a simple frictional model. On the other hand the shape and the length of the deposit are not well reproduced. This is probably due to several factors, which cannot be taken into account 
in a continuum model, such as the interaction between the sphere and their rotatory and relative internal movements. Nevertheless these results demonstrate that for small granular flows the frictional rheology is enough to give good estimations of their propagation.
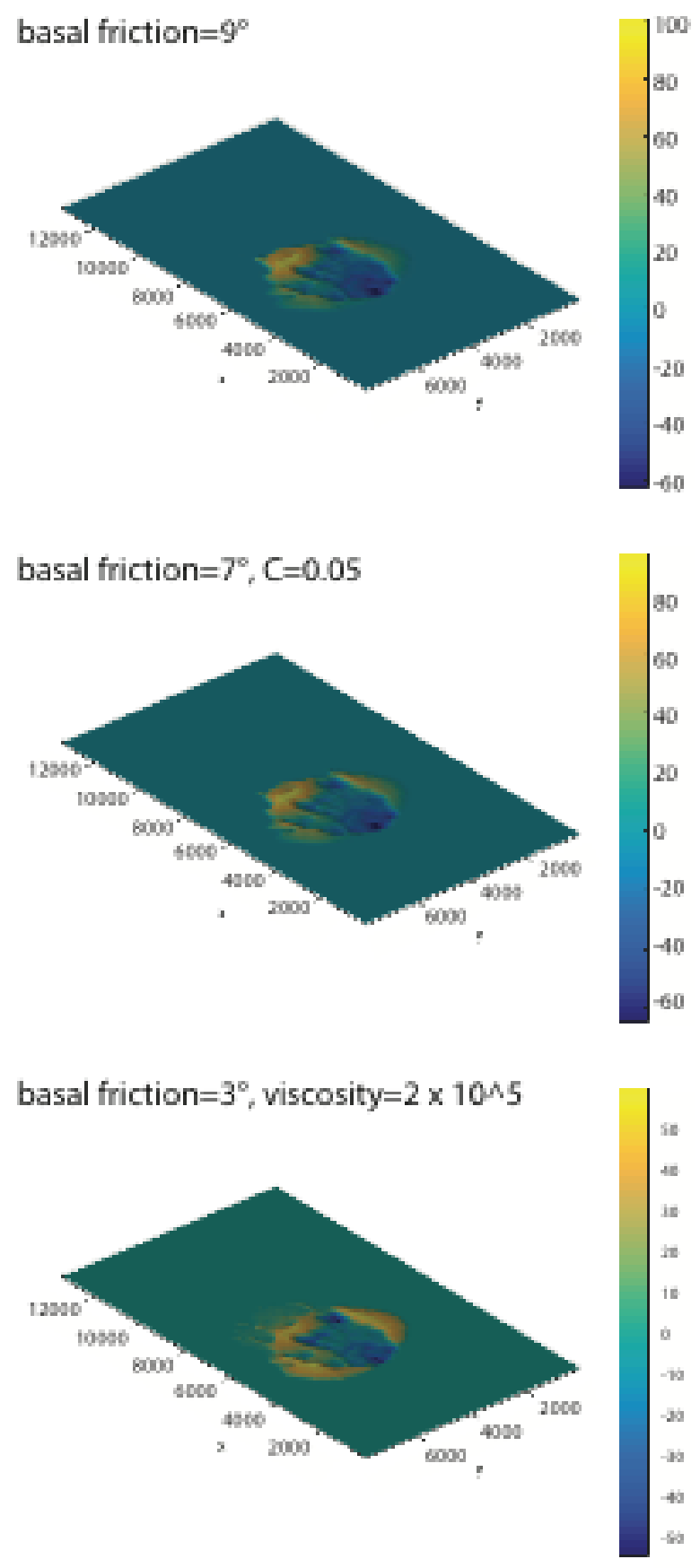

Figure 7. Difference in between final deposit given by simulations and DEM of actual topography. Note that scale bars vary between the plot

For what concerns the rock avalanche analysed, results using a purely frictional model confirm what is already known as one of the main characteristic of these type of phenomena and what have been also observed by Kelfoun and Druitt (2005) who carried out simulations with VolcFlow for the Socompa debris avalanche, i.e. their runout cannot be repro- duced using rock debris basal frictional angles. The angle of friction used needs to be much lower (Corominas, 1996). Acceptable simulations have been obtained in this case using an angle of $9^{\circ}$ which is the same as the apparent friction angle measured in the field. In addition neither the thickness neither the lateral spreading of the final deposit can be reproduced. In particular the mass cannot overcome a positive discontinuity in the topography. The same is obtained using the Voellmy rheology, with which we could only have a slightly better thickness distribution but we couldn't overcome the topographical obstacle. This is possible only assuming very low friction angle (up to $3^{\circ}$ ) and a highly viscous behavior. The similarity of this type of landslide with a viscous flow has been already pointed out by Cruden and Varnes (1996) in their afore-mentioned definition. On the other hand similar results could be obtained here changing as well the values of the cohesion and the low accuracy of the digital terrain model does not allow us to speculate on the most suitable rheology. Nevertheless it is interesting here to highlight the sensitivity to changes in the topography in the simulation of the propagation of this type of flow also in relation with the rheology used, confirming as well the importance of the regularity of the pathway in the mobility of rock avalanches, already pointed out by several authors (e.g. Heim (1932), Friedmann et al. (2006), Manzella and Labiouse (2013)).

In addition, comparison between results of simulations of the experiment and of the real case allowed us stressing out further the importance of the scale of the phenomenon and of the initial coherence of the mass. In fact for what concerns the scale, it can be seen how a simple frictional model works well when we are dealing with laboratory scale, but it is not efficient any more for the field one.

For what concerns the initial coherence it has to be underlined here that for the experiment the mass starts as a completely loose, non-coherent material from the beginning. In rock avalanche cases history, this does not happen. In general masses fail as a coherent or semi-coherent mass, which disaggregates and shatters only during the propagation and deposition. This can happen quite in proximity of the scar or the mass can keep a certain degree of compactness for a longer distance, depending on the strength of the rock and the magnitude of the impact. Simulation results show that the lateral spreading of an unconstrained flow it is well reproduced when the mass is loose from the start but it is not when, as in the real case, the mass is compact when it fails. As a consequence, even if in the Potrero de Leyes case there were no lateral constrains, the mass has not propagated laterally as it would be expected. This has also consequences on the mobility of the flow, as already stated by Davies (1982) and demonstrated by Manzella et al. (2013) and Manzella and 
Labiouse (2013), since it has probably reduced the dissipation of energy in the initial part of the emplacement and could thus have been one of the causes of the high mobility of this event.

\section{ACKNOWLEDGMENTS}

Acknowledgments go to the MEMOVOLC project for having funded one month research visit of $\mathrm{I}$. Manzella at the Laboratoire Magmas et Volcans (project: Volcanic and non-volcanic landslide hazard: a combined experimental and numerical multidisciplinary approach) and to the Fondation Ernst et Lucie Schmidheiny, C. Bonadonna and F.Arlaud for having supported and contributed in the building of the laboratory set-up.

\section{REFERENCES}

Azzoni, A., Chiesa, S., Frassoni, A. \& Govi, M. 1992. The Valpola Landslide. Engineering Geology, 33, 59-70.

Charrière, M., Humair, F., Froese, C., Jaboyedoff, M., Pedrazzini, A. \& Longchamp, C. 2016. From the source area to the deposit: Collapse, fragmentation, and propagation of the Frank Slide. Geological Society of America Bulletin, 128, 332-351.

Constantinescu, R., Thouret, J.-C. \& Irimuş, I.-A. 2011. Computer modeling as tool for volcanic hazards assessment: an example of pyroclastic flow modeling at El Misti volcano, Southern Peru. Geographia Technica, 2, 1-14.

Corominas, J. 1996. The angle of reach as a mobility index for small and large landslides. Canadian Geotechnical Journal, 33, 260-271.

Cruden, D. M. \& Martin, C. D. 2007. Before the frank slide. Canadian Geotechnical Journal, 44, 765-780.

Cruden, D. M. \& Varnes, D. J. 1996. Landslide types and processes. Special Report - National Research Council, Transportation Research Board, 247, 36-75.

Davies, T. R. H. 1982. Spreading of rock avalanche debris by mechanical fluidization. Rock Mechanics Felsmechanik Mécanique des Roches, 15, 9-24.

Davies, T. R. H. \& Mcsaveney, M. J. 1999. Runout of dry granular avalanches. Canadian Geotechnical Journal, 36, 313-320.

Evans, S. G., Clague, J. J., Woodsworth, G. J. \& Hungr, O. 1989. The Pandemonium Creek Rock Avalanche, British-Columbia. Canadian Geotechnical Journal, 26, 427-446.

Evans, S. G., Roberts, N. J., Ischuk, A., Delaney, K. B., Morozova, G. S. \& Tutubalina, O. 2009. Landslides triggered by the 1949 Khait earthquake, Tajikistan, and associated loss of life. Engineering Geology, 109, 195-212.

Friedmann, S. J., Taberlet, N. \& Losert, W. 2006. Rockavalanche dynamics: insights from granular physics experiments. International Journal of Earth Sciences, 95, 911-919.

Heim, A. 1932. Bergsturz und menschenleben, Zurich, Frets und Wasmuth.
Hermanns, R., Folguera, A., Penna, I., Fauqué, L. \& Niedermann, S. 2011. Landslide Dams in the Central Andes of Argentina (Northern Patagonia and the Argentine Northwest). In: EVANS, S. G., HERMANNS, R. L., STROM, A. \& SCARASCIAMUGNOZZA, G. (eds.) Natural and Artificial Rockslide Dams. Springer Berlin Heidelberg.

Hungr, O. 1995. A model for the runout analysis of rapid flow slides, debris flows, and avalanches. Canadian geotechnical journal, 610-623.

Hungr, O., Corominas, J. \& Eberhardt, E. Estimating landslide motion mechanism, travel distance and velocity. Proceedings of the International Conference on Landslide Risk Management, 2005. 99-128.

Hungr, O., Leroueil, S. \& Picarelli, L. 2013. The Varnes classification of landslide types, an update. Landslides, 11, 167-194.

Iverson, R. M. \& Denlinger, R. P. 2001. Flow of variably fluidized granular masses across three-dimensional terrain I. Coulomb mixture theory. Journal of Geophysical Research B: Solid Earth, 106, 537-552.

Jaboyedoff, M. \& Derron, M.-H. 2005. A new method to estimate the infilling of alluvial sediment of glacial valleys using a sloping local base level. Geografia Fisica e Dinamica Quaternaria, 28, 37-46.

Kelfoun, K. \& Druitt, T. H. 2005. Numerical modeling of the emplacement of Socompa rock avalanche, Chile. Journal of Geophysical Research-Solid Earth, 110, 13.

Kelfoun, K., Samaniego, P., Palacios, P. \& Barba, D. 2009. Testing the suitability of frictional behaviour for pyroclastic flow simulation by comparison with a well-constrained eruption at Tungurahua volcano (Ecuador). Bulletin of Volcanology, 71, 1057-1075.

Longchamp, C., Charrière, M., Derron, M.-H. \& Jaboyedoff, M. Experiments on substratum roughness, grainsize and volume influence on the motion and spreading of rock avalanches. 4th Pan-American Conference on Soil Mechanics and Geotechnical Engineering, 2011 Toronto. Canadian Geotechnical Society.

Mangeney-Castelnau, A., Bouchut, F., Vilotte, J. P., Lajeunesse, E., Aubertin, A. \& Pirulli, M. 2005. On the use of Saint Venant equations to simulate the spreading of a granular mass. Journal of Geophysical Research B: Solid Earth, 110, 1-17.

Manzella, I. 2008. Dry rock avalanche propagation: unconstrained flow experiments with granular materials and blocks at small scale Ph.D Ph.D n4032, Ecole Polytechnique Fédérale de Lausanne.

Manzella, I., Einstein, H. H. \& Grasselli, G. 2013. DEM and FEM/DEM Modelling of Granular Flows to Investigate Large Debris Avalanche Propagation. In: MARGOTTINI, C., CANUTI, P. \& SASSA, K. (eds.) Landslide Science and Practice. Springer.

Manzella, I. \& Labiouse, V. Extension of the fringe projection method to measure shape and position of the centre of mass of granular flow deposit. 2008a Goa. 4547-4554.

Manzella, I. \& Labiouse, V. 2008b. Qualitative analysis of rock avalanches propagation by means of physical modelling of non-constrained gravel flows. Rock Mechanics and Rock Engineering, 41, 133-151.

Manzella, I. \& Labiouse, V. 2009. Flow experiments with gravel and blocks at small scale to investigate 
parameters and mechanisms involved in rock avalanches. Engineering Geology, 109, 146-158.

Manzella, I. \& Labiouse, V. 2013. Empirical and analytical analyses of laboratory granular flows to investigate rock avalanche propagation. Landslides, 10, 23-36.

Nicoletti, P. G. \& Sorriso-Valvo, M. 1991. Geomorphic controls of the shape and mobility of rock avalanches. Geological Society of America Bulletin, 103, 13651373.

Penna, I. M., Abellan, A., Humair, F., Jaboyedoff, M. \& Fauqué, L. 2015a. The role of tectonic deformation on the occurrence of a rock avalanche at the Pampeanas Ranges (Argentina), in press in Geomorphology.

Penna, I. M., Derron, M.-H., Volpi, M. \& Jaboyedoff, M. 2013. Analysis of past and future dam formation and failure in the Santa Cruz River (San Juan province, Argentina). Geomorphology, 186, 28-38.

Penna, I. M., Hermanns, R. L., Daicz, S., Suriano, J. \& Tedesco, A. M. 2015b. Effects of tectonic deformation and landslides in the erosion of a mountain plateau in the transitional zone between the central and Patagonian Andes. American Journal of Science, 315, 257-274.

Pirulli, M. \& Mangeney, A. 2008. Results of back-analysis of the propagation of rock avalanches as a function of the assumed rheology. Rock Mechanics and Rock Engineering, 41, 59-84.

Pudasaini, S. P. \& Hutter, K. 2007. Avalanche Dynamics: Dynamics of Rapid Flows of Dense Granular Avalanches.

Savage, S. B. \& Hutter, K. 1989. Motion of a finite mass of granular material down a rough incline. Journal of Fluid Mechanics, 199, 177-215.

Scheidegger, A. E. 1973. On the prediction of the reach and velocity of catastrophic landslides. Rock Mechanics Felsmechanik Mécanique des Roches, 5, 231-236.

Varnes, D. J. 1978. Slope movement and types of processes. Landslides: Analysis and Control, 11-33. 